\title{
HEALTH POLICY \\ The Pace of Change in Medical Practice and Health Policy: Collision or Coexistence?
}

\author{
Neda Laiteerapong, MD, MS and Elbert S. Huang, MD, MPH \\ Department of Medicine, Section of General Internal Medicine and Center for Translational and Policy Research of Chronic Diseases, University of \\ Chicago, Chicago, IL, USA.
}

Medical practice and health policy are both changing rapidly. While the adopting of changes is not new for physicians, the pace of change in standards of care, marked by advances and reversals, has accelerated over the course of the past decade. A recurring new theme in medical practice has been an emphasis on tailoring treatment plans to individual patients. Physicians have had to simultaneously absorb new processes in the health care system brought about by the Health Information Technology for Economic and Clinical Health (HITECH) Act in 2009 and the Affordable Care Act (ACA) in 2010. The ability of physicians to maintain standards of care that focus on individual patients may conflict with changes resulting from new health policies that emphasize population health management. Primary care physicians may be one of the few collective voices capable of identifying areas where population-level health policies conflict with the care of individual patients, and policymakers should include practicing primary care physicians in the form of community boards in order to ensure the development of new health policies that provide sustainable high-value patient care.

KEY WORDS: Health policy; Primary care; Health care reform.

$\mathrm{J}$ Gen Intern Med 30(6):848-52

DOI: $10.1007 / \mathrm{s} 11606-015-3182-0$

(c) Society of General Internal Medicine 2015

\section{INTRODUCTION}

Primary care physicians recognize that medical practice and health policy are both changing rapidly. Decades of advances in clinical practice and public health have contributed to gains in population health, while health care reform in the U.S. promises to promote greater accessibility, quality, and efficiency in the health care system. The great challenge is that advances in medical practice and health policy may be making their way separately, and with little coordination, they may clash at the level of the practicing primary care physician, leading to health policies that promote outdated standards and impede clinical practice. To avoid this collision, we need to ensure that primary care physicians have an avenue to

Received June 6, 2014

Revised December 15, 2014

Accepted December 23, 2014

Published online January 22, 2015 inform policymakers of healthcare system inefficiencies and barriers to providing high-quality care.

\section{PACE OF CHANGE IN MEDICAL PRACTICE}

The pace of change in medical practice has been rapid, with frequent advances and reversals. Biomedical research has led to major accomplishments, including the near eradication of polio and the development of life-saving options for renal disease, AIDS, and cancer. To support these achievements, there has been a parallel rise in approved FDA drugs (Fig. 1). ${ }^{1}$ The rapid advancements in medical information are mirrored by the $3 \%$ annual increase in new scientific journals from 1900 to $1996,{ }^{2}$ and nearly 2 million scientific research articles published in 2012 alone. ${ }^{3}$ This continued proliferation of medical advancements has resulted in an exponential growth of medical knowledge, increased complexity of medical practice, and greater medical specialization., ${ }^{4,5}$

Reversals in medical practice also occur regularly, requiring significant changes in standards of care, workflow, and decision-making. Landmark clinical reversals have been witnessed within the last two decades: hormone replacement therapy is no longer routinely recommended for postmenopausal women, ${ }^{6,7}$ rate control is considered to be equivalent or superior to rhythm control in atrial fibrillation, ${ }^{8}$ and prostate cancer screening is no longer routinely recommended. ${ }^{9}$ While one would expect reversals to be infrequent, over the last decade, $40 \%$ of the articles in the New England Journal of Medicine that tested standards of care resulted in reversals in clinical practice protocols. ${ }^{10}$ Major changes to guideline recommendations are also common; for example, the 2013 guideline for cholesterol management emphasizes statin therapy based on cardiovascular risk instead of cholesterol levels. ${ }^{11}$

This growing aggregation of advances and reversals presents a significant challenge to physicians attempting to stay up to date. Historically, there has been an average 17-year lag between medical discoveries and implementation into clinical practice. ${ }^{12,13}$ With the acceleration of changes in clinical medicine, coupled with normal lag times in dissemination, there is a higher probability than ever before that physicians, within just a few years of leaving their training, may not be practicing contemporary standards of care. 


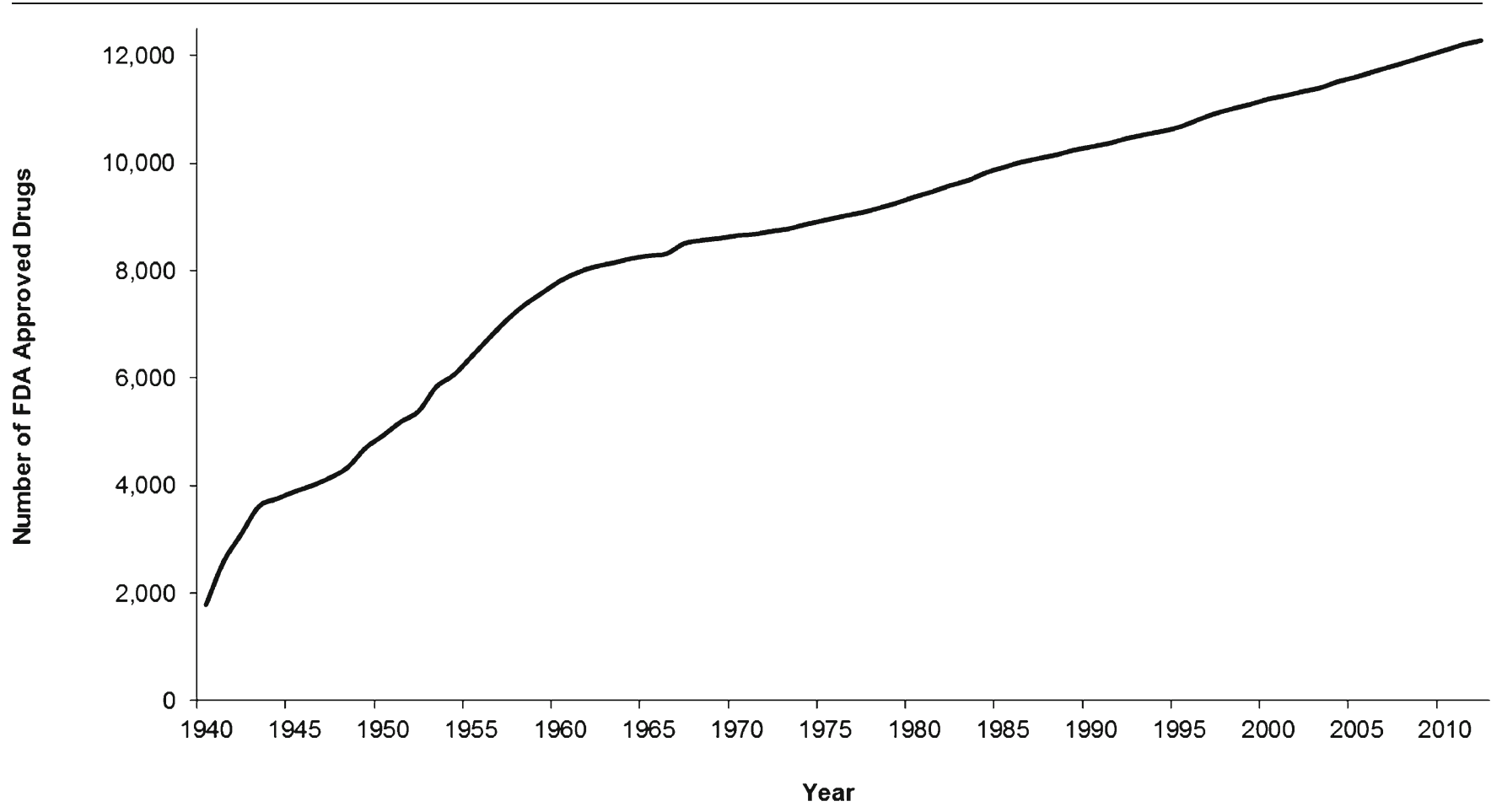

Fig. 1 FDA approved drugs by year

\section{PACE OF CHANGE IN HEALTH POLICY}

The pace of change in health policy has also accelerated. The passage of the Health Information Technology for Economic and Clinical Health (HITECH) Act in 2009 and the Affordable Care Act (ACA) in 2010 ushered in a period of dramatic change in U.S. health care policy, and these policy changes are responsible for rapid changes in the clinical practice environment. As a result of the HITECH Act, the adoption of electronic health record systems has grown exponentially, from only $18 \%$ of office-based physician practices in 2001 to nearly $80 \%$ in $2013 .{ }^{14}$ The ACA has led to seismic shifts in Medicaid enrollment ${ }^{15,16}$, with uncertain implications as to how primary care physicians and health care systems will respond. ${ }^{17}$

\section{MEDICAL PRACTICE AND HEALTH POLICY: A COLLISION}

Ideally, changes in medical practice and health policy should emphasize each leg of the triple aim of better health and better care at a lower cost. ${ }^{18}$ However, changes in medical practice, by their very nature, lead to changes in basic definitions of what represents "better care." The shifting definition of ideal medical practice is a fundamental challenge in health policies that are always at risk of promoting standards that are outdated. Unfortunately, there is no active coordination of these changes in medical practice and health policy.
An illustrative example of the collision between medical practice and policy resides in the lagging updates for performance measures that are used by most health policies to measure quality of care. Since at least 2000, the National Committee for Quality Assurance (NCQA) Health Plan and Healthcare Effectiveness Data and Information Set (HEDIS) have recommended a measure for reporting the proportion of patients with diabetes with appropriate glycemic control, defined as hemoglobin A1c of $<7.0 \%$. However, since 2002, the American Diabetes Association, which sets widely used standards of care for glycemic control, has recommended that glycemic targets should be individualized based on diabetes duration, life expectancy, and comorbid diseases. ${ }^{19}$ It was not until 2009 that the NCQA definition of appropriate glycemic control was revised to an A1c of $<8.0 \%$, and only after the 2008 publication of the ACCORD trial showing harm from intensive glycemic control. ${ }^{20}$ This same lag will likely occur for cholesterol-related performance measures. ${ }^{11}$ With shifting targets in clinical standards of care, how is health policy able to take aim at improving the health of the U.S. population? Additionally, performance measures are focused on single conditions for which the quality of care can be objectively assessed with laboratory or radiologic data - e.g., diabetes and heart failure - yet many highly prevalent conditions do not have such easy markers of quality (e.g., cancer), and most patients have multiple chronic conditions. ${ }^{21,22}$

The clash between medical practice and health policy arises not only from a lack of coordination, but from a fundamental difference in their respective goals as well. Health policy is focused on improving and managing population health, 
cutting unnecessary cost and waste, and eliminating unnecessary variation in clinical practice. ${ }^{23}$ In addition, the shaping of health policy is heavily influenced by politics, which does not have the singular focus of improving health. The highly contentious political discourse surrounding the ACA clearly demonstrates the politicized nature of health policy. In contrast, medical practice is singularly directed at improving the health of patients, one at a time, with little regard for cost, and increasingly emphasizes individualized tailoring of care based on clinical characteristics, genetic markers, and patient preferences, which may explain some of the high variation in clinical practice. $^{24,25}$

The emphasis on personalization in medical practice creates problems with regard to health policy. If personalized care is the standard of care, how do we measure and document its delivery? Highly personalized care can be very challenging to define using administrative claims, the typical data source for performance measurement. Highly personalized care also requires additional time to consider and discuss options with patients, exacerbating the pressures that physicians already feel to improve access, lower costs, and manage populations. ${ }^{26,27}$ Physicians must also balance personalized care with the growing adoption of protocol-based care. ${ }^{28}$ How do we ensure that providers can carry out contemporary clinical recommendations that emphasize individualization while increasing the efficiency of the health care system?

\section{MEDICAL PRACTICE AND HEALTH POLICY: COEXISTENCE}

While there are several reasons that medical practice and health policy may collide, there are equally abundant examples of how new policies are symbiotic with current medical practice. Recent policy changes have provided unique incentives for medical practice to enter the 21 st century. For example, the HITECH Act implemented funding for the Medicare and Medicaid Electronic Health Record (EHR) Incentive Programs, which provided financial incentives for meaningful use of EHRs. This program requires the reporting of quality measures at all stages of implementation. Between 2011 and 2013, over 250,000 providers participated in this incentive program, and were paid a median $\$ 29,760$ (interquartile range, $\$ 14,700$ to $\$ 29,760) .^{29}$ The widespread adoption of EHRs in clinical practice represents a crucial tipping point for this country in the ability to measure population-level quality of care. Additionally, by leveraging clinical repositories and computing power, the EHR may also be a vehicle for delivering highly individualized care recommendations for common and rare diseases at the point of care.

Another example of an innovative health policy that provides a financial incentive to improve care from the vantage point of both patient populations and individual patients is the Medicare Comprehensive Primary Care (CPC) initiative. ${ }^{30}$ This four-year multi-payer pilot offers its practices population-based care management fees and shared savings opportunities when they provide five primary care functions: risk-stratified care management, access and continuity, planned care for chronic conditions and preventive care, patient and caregiver engagement, and coordination of care across the medical neighborhood. As part of its patient and caregiver engagement function, the initiative requires practices to use decision aids in order to engage patients and families in goal-setting and shared decision-making. Currently, there are 481 practice sites participating, including 2,347 providers and 2.5 million patients. The goal of this program is closely aligned with the triple aim, and results will inform future CMS policy.

\section{FUTURE DIRECTIONS}

As a result of the upheaval in clinical practice due to new legislation, the clinical environment is changing rapidly. Primary care physicians are especially well-poised to act as first reporters of collisions between new health policies and clinical practice. At this time, however, primary care physicians have few avenues through which to report these collisions. The traditional processes for developing performance measures and federal rules for health policy are not accessible to busy practicing physicians. Furthermore, these processes, by their nature, are not rapidly responsive. Policymakers should make it easier for primary care physicians to report conflicts between clinical practice and health policy and to suggest fixes. While professional medical societies may seem like a reasonable option for providing a voice for primary care physicians to communicate with policymakers, membership in the largest such group, the American Medical Association, has waned to only 217,000 members, only about $15 \%$ of practicing physicians, ${ }^{31}$ casting doubt on the ability of this organization to speak to the needs of primary care physicians.

Policymaking organizations should consider having community boards made up of practicing primary care physicians in order to ensure that policies are practical, insightful, and help to improving population outcomes. There may be valuable lessons learned from community-based participatory research and the Patient-Centered Outcomes Research Institute, which have advocated for the early involvement of patients in clinical research. The concept of a community board of practicing physicians is not new; the Practicing Physicians Advisory Council was actually established by Congress as part of section 1860(a) of the Social Security Act [42 U.S.C.1395ee(a)] in order to provide direct feedback to the Centers for Medicare \& Medicaid Services (CMS). However, this policy was repealed by section $3134(\mathrm{~b})(2)$ of the Patient Protection and Affordable Care Act prior to its implementation. $^{32}$

An example of a policy that could have benefitted from the insights of practicing primary care providers is the Medicare "Extended Care Benefit." 33 This benefit requires an inpatient 
hospital stay of at least 3 days prior to receiving post-discharge coverage for rehabilitation in a skilled nursing facility. When this benefit was established in the late 1970s, the average length of stay closely matched 3 days. However, the current average length of stay is closer to 1.5-2 days, and many patients may linger in hospitals in order to obtain skilled nursing facility coverage. While the policy has been reversed and reinstated over the years, it has not been adapted to the needs of individual patients until recently. Currently, the CMS Innovation Center is offering a waiver of the 3-day hospitalization rule to accountable care organizations (ACOs) participating in the Pioneer ACO Model. ${ }^{34}$ While this waiver is a step forward in terms of providing more patient-centered care, primary care providers have encountered this logistic hurdle for over 30 years, and it is likely that, given the opportunity, they could have provided CMS with valuable insights into how to tailor this program to improve patient outcomes while saving hospital days.

\section{CONCLUSIONS}

As medical practice and health policies continue to develop, strategies to connect these areas will be increasingly important for ensuring that advances in medical practice are not at odds with advances in health policy. Because of the front-end experience of primary care physicians, it would behoove policymakers to consider including practicing primary care physicians in the development of new policies, such that future health policies will help bolster, rather than clash with, medical practice.

Contributors: None.

Funders: None.

\section{Prior Presentations: None.}

Conflict of Interest: The authors (Laiteerapong and Huang) have no conflicts of interest to disclose.

Financial Support: Dr. Laiteerapong is supported by National Institute of Diabetes and Digestive and Kidney Diseases (NIDDK) award K23 DK097283. Dr. Laiteerapong and Dr. Huang are members of the NIDDK Chicago Center for Diabetes Translation Research at the University of Chicago (P3O DK092949).

Corresponding Author: Neda Laiteerapong, MD, MS; Department of Medicine, Section of General Internal Medicine and Center for Translational and Policy Research of Chronic DiseasesUniversity of Chicago, 5841 S Maryland Ave, MC 2007, Chicago, IL 60637, USA (e-mail: nlaiteer@medicine.bsd.uchicago.edu).

\section{REFERENCES}

1. Food and Drug Administration. Is it true FDA is approving fewer new drugs lately? Available at: http://www.fda.gov/downloads / AboutFDA/Transparency/Basics/UCM247465.pdf. Accessed January 2, 2015.

2. Mabe M, Amin M. Growth dynamics of scholarly and scientific journals Scientometrics. 2001;51:147-62.
3. Hughes DA, Bagust A, Haycox A, Walley T. The impact of non-compliance on the cost-effectiveness of pharmaceuticals: a review of the literature. Health Econ. 2001;10:601-15.

4. Detsky AS, Gauthier SR, Fuchs VR. Specialization in medicine: how much is appropriate? JAMA : the journal of the American Medical Association. 2012;307:463-4.

5. Meltzer DO. Social science insights into improving workforce effectiveness: examples from the developing field of hospital medicine. J Public Health Manag Pract. 2009;15:S18-23.

6. Rossouw JE, Anderson GL, Prentice RL, et al. Risks and benefits of estrogen plus progestin in healthy postmenopausal women: principal results From the Women's Health Initiative randomized controlled trial. JAMA: the journal of the American Medical Association. 2002;288:321-33.

7. Anderson GL, Limacher M, Assaf AR, et al. Effects of conjugated equine estrogen in postmenopausal women with hysterectomy: the Women's Health Initiative randomized controlled trial. JAMA: the journal of the American Medical Association. 2004;291:1701-12.

8. Wyse DG, Waldo AL, DiMarco JP, et al. A comparison of rate control and rhythm control in patients with atrial fibrillation. $N$ Engl $\mathrm{J}$ Med. 2002;347:1825-33.

9. Gaseem A, Barry MJ, Denberg TD, Owens DK, Shekelle P. Screening for prostate cancer: a guidance statement from the clinical guidelines committee of the American College of Physicians. Ann Intern Med. 2013; 158:761-9.

10. Prasad V, Vandross A, Toomey C, et al. A decade of reversal: an analysis of 146 contradicted medical practices. Mayo Clin Proc. 2013;88:790-8.

11. Stone NJ, Robinson JG, Lichtenstein AH, et al. 2013 ACC/AHA guideline on the treatment of blood cholesterol to reduce atherosclerotic cardiovascular risk in adults: a report of the American College of Cardiology/American Heart Association Task Force on Practice Guidelines. J Am Coll Cardiol. 2014;63:2889-934.

12. Morris ZS, Wooding S, Grant J. The answer is 17 years, what is the question: understanding time lags in translational research. Journal of the Royal Society of Medicine. 2011;104:510-20.

13. Westfall JM, Mold J, Fagnan L. Practice-based research-"Blue Highways" on the NIH roadmap. JAMA: the journal of the American Medical Association. 2007;297:403-6.

14. Hsiao C-J, Hing E. Use and characteristics of electronic health record systems among office-based physician practices: United States, 20012013. NCHS data brief, no 143. Hyattsville: National Center for Health Statistics; 2014.

15. Centers for Medicare \& Medicaid Services. Medicaid \& CHIP: April 2014 Monthly Applications, Eligibility Determinations, and Enrollment Report. Available at: http://medicaid.gov/medicaid-chip-program-information/ program-information/downloads/april-2014-enrollment-report.pdf. Accessed January 2, 2015.

16. Sommers BD, Kenney GM, Epstein AM. New evidence on the Affordable Care Act: coverage impacts of early medicaid expansions. Health Aff (Millwood). 2014;33:78-87.

17. Rhodes KV, Kenney GM, Friedman AB, et al. Primary care access for new patients on the eve of health care reform. JAMA internal medicine. 2014; 174:861-9.

18. Berwick DM, Nolan TW, Whittington J. The triple aim: care, health, and cost. Health Aff (Millwood). 2008;27:759-69.

19. American Diabetes Association. Standards of medical care for patients with diabetes mellitus. Diabetes Care. 2002;25:213-29.

20. Gerstein HC, Miller ME, Byington RP, et al. Effects of intensive glucose lowering in type 2 diabetes. N Engl J Med. 2008;358:254559.

21. Laiteerapong $\mathbf{N}$, Iveniuk J, John PM, Laumann EO, Huang ES. Classification of older adults who have diabetes by comorbid conditions, United States, 2005-2006. Prev Chronic Dis. 2012;9:E100.

22. Schneider KM, O Donnell BE, Dean D. Prevalence of multiple chronic conditions in the United States' Medicare population. Health Qual Life Outcomes. 2009;7:82.

23. Wennberg $\mathbf{J}$, Gittelsohn A. Variations in medical care among small areas. Scientific American. 1982;246:120-34.

24. Chin MH, Clarke AR, Nocon RS, et al. A roadmap and best practices for organizations to reduce racial and ethnic disparities in health care. J Gen Intern Med. 2012;27:992-1000.

25. Inzucchi SE, Bergenstal RM, Buse JB, et al. Management of hyperglycemia in type 2 diabetes: a patient-centered approach: position statement of the American Diabetes Association (ADA) and the European Association for the Study of Diabetes (EASD). Diabetes Care. 2012;35:1364-79. 
26. Yarnall KS, Pollak KI, Ostbye T, Krause KM, Michener JL. Primary care: is there enough time for prevention? Am J Public Health. 2003;93:635-41.

27. Ostbye T, Yarnall KS, Krause KM, Pollak KI, Gradison M, Michener JL. Is there time for management of patients with chronic diseases in primary care? Ann Fam Med. 2005;3:209-14.

28. Pronovost $\mathbf{P}$, Needham D, Berenholtz $\mathbf{S}$, et al. An intervention to decrease catheter-related bloodstream infections in the ICU. N Engl J Med. 2006;355:2725-32.

29. Centers for Medicare \& Medicaid Services. Medicare and Medicaid Electronic Health Records Incentive Program Payment and Registration Data. Available at: http://www.cms.gov/Regulations-and-Guidance/Legislation/EHRIncentivePrograms/DataAndReports.html. Accessed January $2,2015$.
30. Centers for Medicare \& Medicaid Services. Comprehensive Primary Care Initiative. Available at: http://innovation.cms.gov/initiatives/comprehensive-primary-care-initiative/. Accessed January 2, 2015.

31. Collier R. American Medical Association membership woes continue. CMAJ. 2011;183:E713-4.

32. Centers for Medicare \& Medicaid Services. Practicing Physicians Advisory Council. Available at: http://www.cms.gov/Regulations-and-Guidance/ Guidance/FACA/ppac.html. Accessed January 2, 2015.

33. Lipsitz LA. The 3-night hospital stay and Medicare coverage for skilled nursing care. JAMA: the journal of the American Medical Association. 2013;310:1441-2.

34. Pham HH, Cohen M, Conway PH. The Pioneer accountable care organization model: improving quality and lowering costs. JAMA: the journal of the American Medical Association. 2014;312:1635-6. 